\title{
Potencial Educativo do Jogo Perguntados
}

\author{
Samira Pirola Santos Mantilla*1, Nathalia Costa Alves ${ }^{2}$
}

\footnotetext{
${ }^{1}$ Pesquisadora, Departamento de Mídias Digitais/Fundação Cecierj. Rua da Ajuda, n $5,15^{\circ}$ andar, Centro

- Rio de Janeiro - RJ - Brasil. smantilla@cecierj.edu.br

2 Pesquisadora, Departamento de Mídias Digitais/Fundação Cecierj. Rua da Ajuda, n 5, $15^{\circ}$ andar, Centro

- Rio de Janeiro - RJ - Brasil. nalves@cecierj.edu.br
}

\section{Resumo}

Os jogos podem ser utilizados para potencializar a educação de forma lúdica e motivadora. O jogo Perguntados é um aplicativo do tipo Quiz on-line muito apreciado por estudantes e público em geral, podendo ser utilizado em dispositivos móveis como smartphones e tablets. O jogo permite ao usuário vincular contas do Facebook para que eles possam desafiar seus amigos entre outras características que motivam o jogador. O objetivo desta pesquisa foi analisar o potencial do uso desse jogo na educação por meio de um questionário disponibilizado no Facebook. Observou-se que a maioria dos usuários concorda que receber bônus (personagens), saber a sua posição no ranking e a vontade de ganhar estimulam o jogador. Além disso, a maioria concorda que ficam concentrados quando estão jogando, aprendem algum conceito durante o jogo, acreditam que o jogo pode ser utilizado como complementar em alguma disciplina e que está adequado à sua maneira de aprender. Entretanto, a maioria (53\%) discorda que, após jogar, fica com vontade de pesquisar assuntos abordados no jogo. Esse jogo pode ser usado na educação por apresentar elementos que estimulam o jogador e por abordar diferentes temas, entretanto, as perguntas deveriam ser feitas por especialistas da área e não pelos próprios jogadores.

Palavras-chave: Jogos eletrônicos; Quiz; Aprendizagem móvel; Educação. 


\title{
Educative Potential of Perguntados Game
}

\begin{abstract}
Games give potential to education in an interesting way. The game Perguntados is an App - a type of online quiz very appreciated by students and the general publicand it can be used on mobile devices such as smartphones and tablets. The game allows the users to synchronize their Facebook account, so they can challenge their friends. Most users agree that receiving badges (characters) and knowing their position in the rankings, encourage the player to win. Additionally, most of the users agree that they stay focused when are playing, they learn some concept during the game, and they believe that the game can be used as a complement in any subject and it is an effective way to learn. However, most users (53\%) disagree that after playing they feel interested in looking for more information about the content of the questions. According to most of the users, the game Perguntados can be used in education by presenting elements that stimulate the player and by addressing different issues, however, questions should be made by experts in each field and not by the players themselves.
\end{abstract}

Key words: Eletronic games; Quiz; Mobile learning; Education. 


\section{Introdução}

O jogo pode ser um ótimo recurso didático ou estratégia de ensino para os educadores, pois estimula o desenvolvimento das habilidades que contribuem no processo de construção do conhecimento. Jogos bem elaborados e explorados podem atingir diferentes objetivos que variam desde o simples treinamento até a construção de um determinado conhecimento. Se utilizados de forma adequada e com mediações por parte dos educadores, os jogos podem acrescentar-se à educação como mais um agente transformador, enriquecendo as aulas de forma divertida e animada, pois brincando também se aprende (Ramos et al., 1995; Grubel et al., 2006).

No campo social, os jogos permitem que as crianças estabeleçam relações de trocas, que aprendam a esperar sua vez, que se acostumem a lidar com regras, conscientizando-se de que podem ganhar ou perder (Ramos et al., 1995).

Com o desenvolvimento tecnológico, surgiu uma nova modalidade de jogos, os jogos eletrônicos. Entretanto, a utilização desse tipo de jogo na área da educação ainda sofre preconceitos, por muitas vezes ser visto como uma perda de tempo, algo em que os jovens acabam se viciando e que não os ensina nada (Medeiros et al.,2012).

Pesquisadores da área da educação vêm demonstrando o potencial pedagógico de jogos eletrônicos como Mustardo et al. (2012) que consideram as seguintes características positivas de jogos eletrônicos - interatividade, capacidade de adaptação e elemento lúdico, que são estruturadas por regras e metas e que possibilitam a aprendizagem por meio do feedback e resolução de problemas. Segundo Tauroco et. al. (2004), os jogos podem ser ferramentas instrucionais eficientes, visto que eles divertem enquanto motivam, facilitam o aprendizado e aumentam a capacidade de retenção do que foi ensinado, exercitando as funções mentais e intelectuais do jogador.

Entretanto, será que um jogo on-line no estilo de Quiz pode ser usado para estimular o processo de ensino aprendizagem? Ao avaliarem um quiz de múltipla escolha gamificado quanto aos aspectos da aprendizagem, engajamento e prazer, Cheong et al. (2013) verificaram que a maioria dos alunos $(77,63 \%)$ de cursos de graduação relacionados à área de TI relataram que estavam engajados o suficiente para completar o quiz e 46,05\% afirmaram que ficaram felizes enquanto o jogavam. Segundo os pesquisadores, os resultados foram positivos, pois $60,53 \%$ dos estudantes afirmaram que o uso do quiz gamificado intensificou o aprendizado. 
Aliado ao fato do potencial dos jogos na educação, observa-se que os estudantes estão muito envolvidos com tecnologias móveis como smatphones e tablets no seu cotidiano. Muitos nem desligam os aparelhos durante as aulas, o que incomoda muitos professores. Será que poderíamos utilizar essa tecnologia a favor da educação? De acordo com Keskin et al. (2011), a aprendizagem móvel (mobile-learning) é um campo de estudo multidisciplinar muito popular em todo o mundo e que tem atraído a atenção de pesquisadores, os quais perceberam o potencial de aplicação de tecnologias móveis para melhorar a aprendizagem.

A aprendizagem móvel ganhou a atenção das pessoas visto que os dispositivos móveis são portáteis, onipresente, de fácil acesso e usados por muitas pessoas. Em alguns países, os dispositivos móveis são mais utilizados do que os próprios computadores. Essa situação mostra que existe um grande potencial para enriquecer a aprendizagem com dispositivos móveis (Keskin et al., 2011).

A prática de ler em dispositivos móveis já está bastante disseminada, seja na leitura de livros digitais, de páginas da internet ou de notícias do dia a caminho do trabalho. Mas já não basta levar somente diversão para dentro dos celulares, smartphones e tablets. Pesquisadores e desenvolvedores já se dedicam a aliar tecnologia e educação por meio de softwares educacionais, nos quais o usuário pode acessar suas apostilas, jogos, exercícios, fóruns, chats, e-mails e videoaulas de maneira integrada em um ambiente on-line que permita aos professores e alunos um grande nível de interação em qualquer lugar e a qualquer hora, o que facilitaria a administração das tarefas diárias dos usuários com pouco tempo para estudar, por exemplo (Mühlbeier et al. , 2012).

Hoje em dia, as pessoas têm a sua disposição muitos jogos gratuitos para smartphones e tablets. Alguns são somente para diversão como, por exemplo, AngryBird, Flying Bob, Candy Crush Saga, Traffic Rush, Pou, Dots etc. Entretanto, outros jogos possuem fins educativos, principalmente para crianças, como ABC do Bita, Matemática fácil, Tabuada de Multiplicar, Você consegue?, Pense+ (ENEM) entre outros.

O jogo Perguntados, por exemplo, é um aplicativo de perguntas e respostas, que aborda diferentes temas, muito utilizado por usuários que procuram diversão. Ele está disponível gratuitamente para download em smartphones e tablets que possuem sistemas operacionais Android, IOS e Windows Phone. 
Esse aplicativo foi lançado em outubro de 2013, está disponível em sete idiomas e já ultrapassou os quatro milhões de usuários em todo o mundo. O objetivo do jogo é vencer desafios por meio de perguntas/quiz que testam o conhecimento do jogador em diferentes áreas do conhecimento: Entretenimento, Ciência, Esportes, Geografia, História e Artes (Zh Tecnologia, 2014).

Nesse jogo, os usuários podem iniciar disputas com amigos da rede social Facebook ou oponentes aleatórios. O jogador pode ainda iniciar um duelo de amigos, onde muitos participantes deverão responder a uma série de perguntas com um tempo máximo de resposta. Cada partida é iniciada a partir da escolha de um oponente e, em seguida, deve-se girar uma roleta que indicará a categoria de cada pergunta. O amigo ou oponente aleatório receberá uma notificação em seu smartphone sinalizando que foi convidado para uma disputa do Perguntados. Se ele aceitar, inicia-se a partida. O jogador deverá responder corretamente às perguntas, pois se ele errar dará a vez ao seu adversário. Para vencer, um dos oponentes deve obter todos os seis personagens que representam cada categoria de perguntas. Os jogadores podem elaborar perguntas dentro das seis categorias que serão avaliadas pelos outros jogadores, tendo assim um caráter colaborativo.

Apesar de ser um jogo com perguntas sobre diferentes áreas do conhecimento, ele não é utilizado na educação. O objetivo desta pesquisa foi analisar o potencial pedagógico do jogo Perguntados a partir de um questionário de opinião de jogadores e sugerir como ele pode ser inserido na educação.

\section{Metodologia}

A pesquisa foi realizada por meio da elaboração e aplicação de um questionário on-line para usuários do jogo Perguntados. O questionário (Figura 1) foi elaborado por meio de um formulário do Google e o link gerado foi compartilhado no Facebook de conhecidos e em páginas relacionadas ao jogo. As questões eram de resposta fechada e uma questão de resposta aberta para sugestão de melhoria do jogo, para que o mesmo pudesse ser utilizado na educação. 


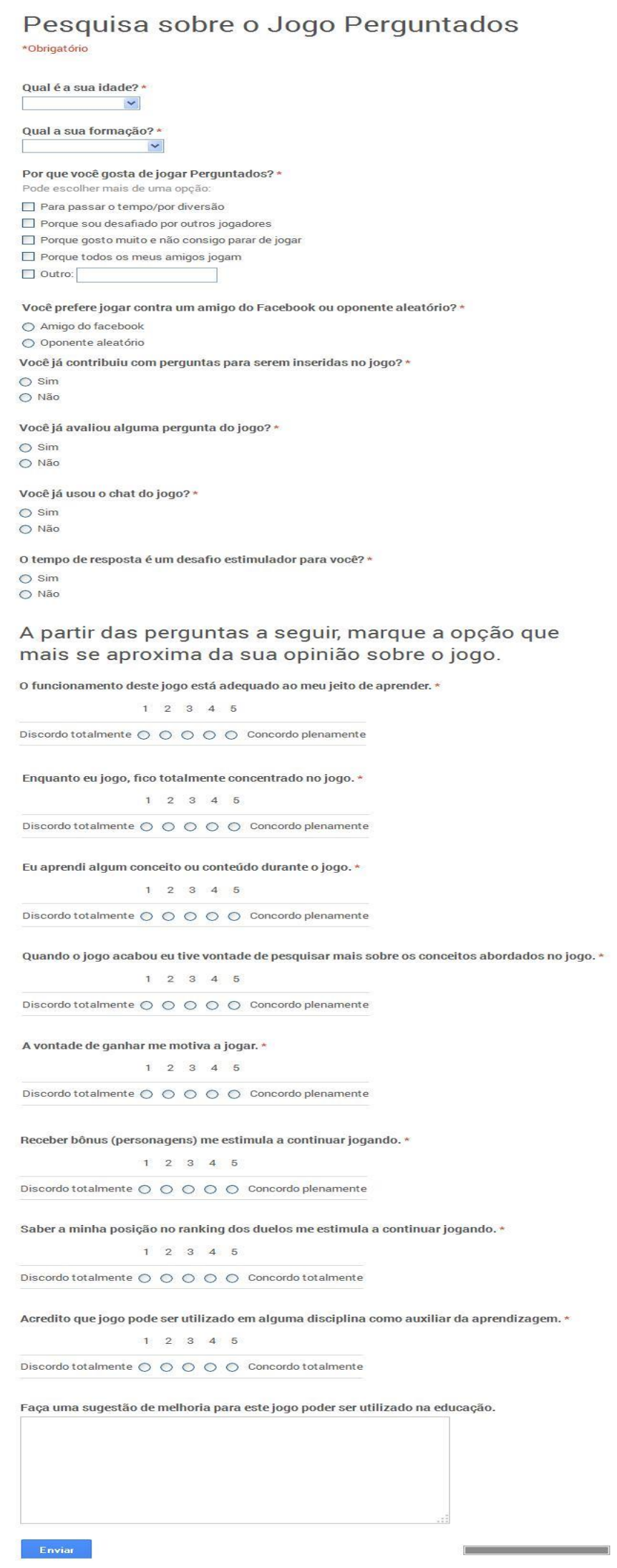

Figura 1 Questionário on-line utilizado na pesquisa 
Utilizou-se a escala Likert para verificar o grau de concordância dos usuários com diferentes perguntas, variando de 1 - discordo totalmente a 5 - concordo totalmente. Os dados foram inseridos em tabelas, onde se calcularam as frequências absolutas, relativas e as médias e foram representados em gráficos com auxílio do Excel.

\section{Resultados e discussão}

Foram respondidos 38 questionários. As figuras 2, 3 e 4 apresentam os resultados obtidos na pesquisa.

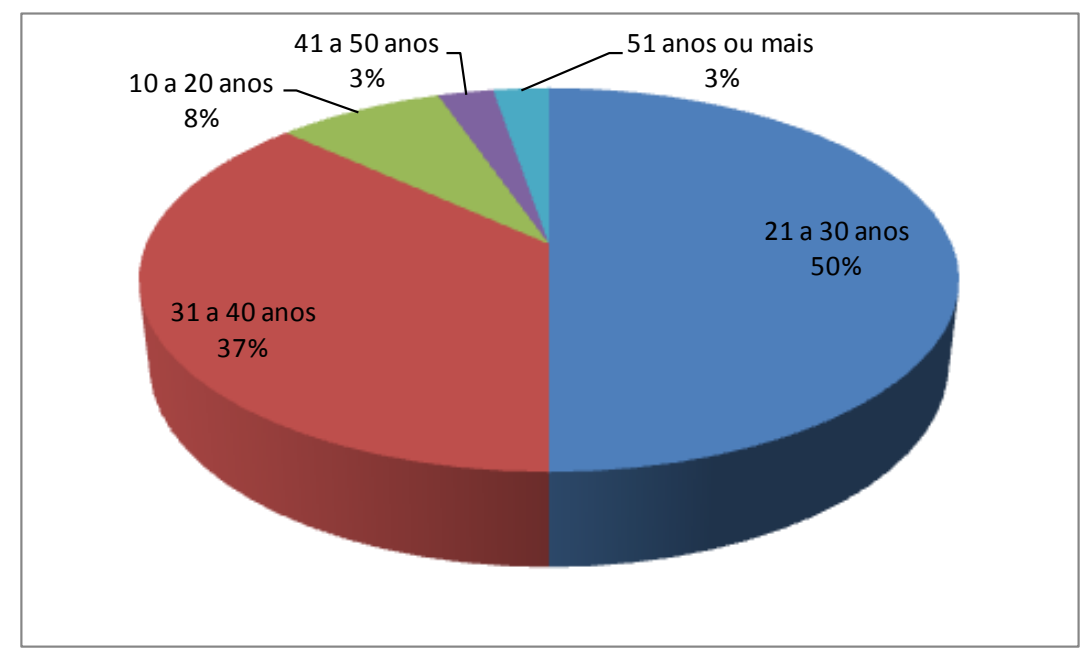

Figura 2. Porcentagem das respostas para a pergunta: "Qual é a sua idade?"

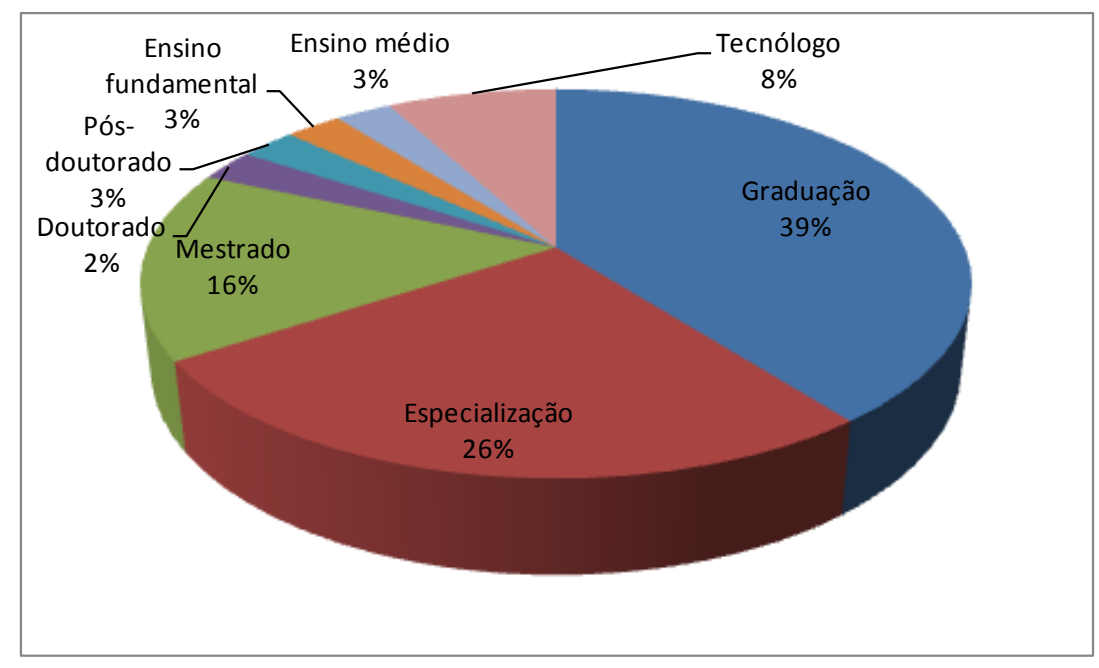

Figura 3. Porcentagem das respostas para a pergunta: "Qual a sua formação?" 


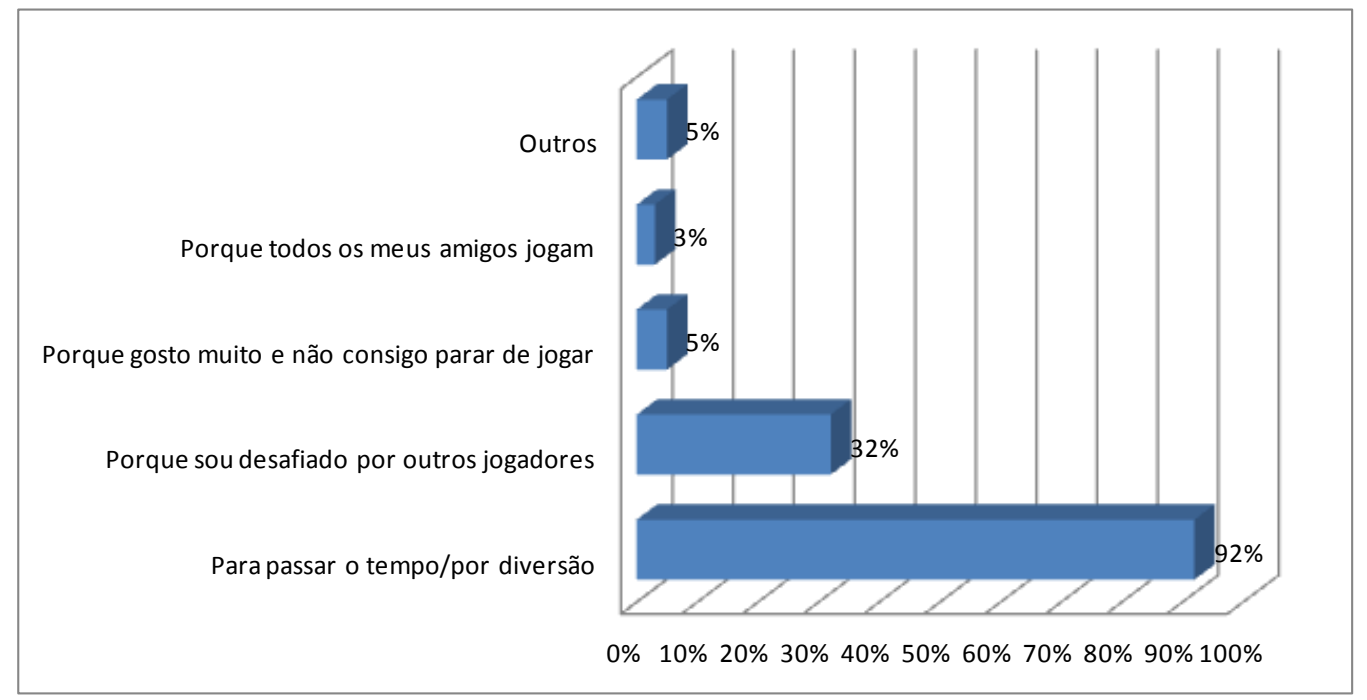

Figura 4. Porcentagem das respostas para a pergunta: "Por que você gosta de jogar Perguntados?"

Analisando-se as Figuras 1 a 4, observa-se que metade dos usuários possui entre 21 e 30 anos (50\%), a maioria possui graduação ou especialização (65\%) e maioria dos usuários joga Perguntados para passar o tempo e/ou por diversão (92\%).

De acordo com os resultados obtidos para as outras perguntas, verificou-se que a maioria dos usuários (66\%) prefere jogar contra um amigo do Facebook do que contra um oponente aleatório; a maioria (71\%) não contribuiu com perguntas para serem inseridas no jogo, entretanto, a maioria (82\%) já avaliou uma pergunta. A ferramenta chat do jogo foi utilizada pela metade dos usuários entrevistados (50\%) e $84 \%$ dos usuários consideram que o tempo de resposta é um desafio estimulador.

Na figura 5, observa-se que somente a pergunta "Quando o jogo acabou eu tive vontade de pesquisar mais sobre os conceitos abordados no jogo" teve uma média de concordância tendendo para a resposta discordo $(2,7)$. As outras tenderam para concordo ou concordo totalmente. 


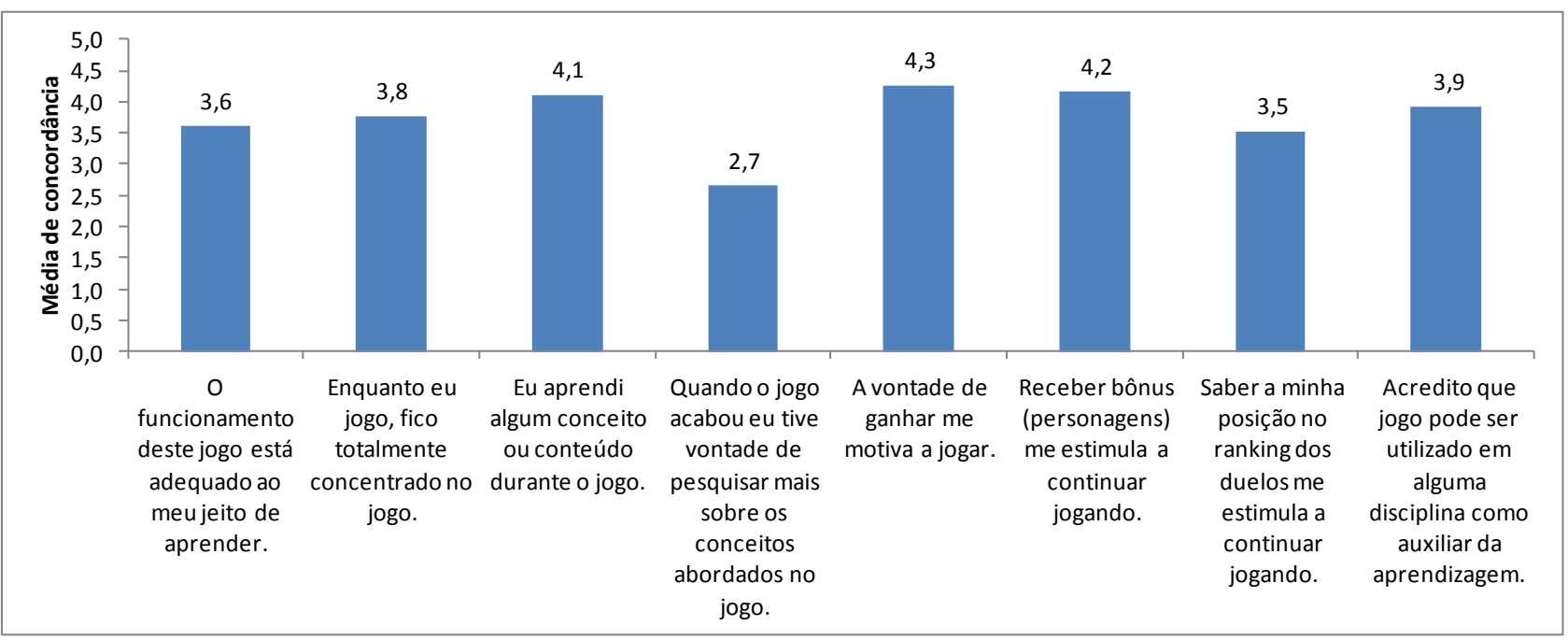

Figura 5. Médias das opiniões dos usuários versus escala de concordância, variando de 1 (discordo totalmente) até 5 (concordo totalmente).

No presente estudo, verificou-se que a maioria dos usuários do jogo Perguntados concorda que receber bônus (personagens), saber a sua posição no ranking e a vontade de ganhar estimulam o jogador. Esses resultados corroboram com Mustardo e Mendonça (2012) que consideram como elementos atrativos dos jogos a satisfação pessoal, o êxito, a superação de desafios, a competição e a possibilidade de representação de papéis.

A maioria dos jogadores também concorda que ficam concentrados quando estão jogando, aprendem algum conceito durante o jogo, acredita que o jogo pode ser utilizado como complementar em alguma disciplina e que está adequado ao seu jeito de aprender. Germano et al. (2011) também verificaram aspectos positivos ao utilizar um quiz como ferramenta de aprendizagem na disciplina de astronomia, onde os alunos identificam como contribuições principais dela: ajudar a identificar temas centrais nas aulas, motivar leitura mais atenta e proporcionar autoavaliação. Na área de saúde mental, Botti et al. (2013) observaram que um software educativo do tipo Quiz apresentou-se como uma alternativa para o ensino de forma motivadora e adequada aos alunos de Enfermagem e demais cursos da saúde, como também aos profissionais de saúde em situações de treinamento/aperfeiçoamento.

De acordo com o resultado da presente pesquisa, a maioria dos usuários discorda que, após jogar, ficam com vontade de pesquisar assuntos abordados no jogo. 
Entretanto, Silva et al. (2010) verificaram que alunos submetidos a um Quiz sobre Genética e Biologia Molecular demonstraram um aumento de interesse nos temas abordados. Isso pode ter ocorrido devido às características das perguntas elaboradas pelos pesquisadores, possuindo caráter mais contextualizado.

Em relação às sugestões dos usuários sobre o jogo, a grande maioria apontou que deveria haver uma revisão ortográfica e gramatical e maior rigor na avaliação das perguntas, que deveria ser feita por profissionais das áreas de conhecimento e não por usuários. Alguns usuários sugeriram que as perguntas fossem todas educativas e que o jogo poderia ser utilizado para reforço de conteúdo apresentado em sala de aula, como atividade extra ou opcional.

Na visão dos usuários da presente pesquisa, para que Perguntados pudesse ser utilizado com fins educacionais, as questões deveriam ser elaboradas, avaliadas e categorizadas por especialistas nas áreas de conhecimento contempladas pelo jogo e não pelos próprios jogadores.

\section{Considerações finais}

O jogo Perguntados apresenta diferentes elementos e características que estimulam o jogador, como bonificação com personagens, competição entre colegas do Facebook, tempo de resposta cronometrado, ranking do usuário e aborda diferentes áreas de interesse. Entretanto, para que ele possa ser utilizado na educação, as perguntas devem ser elaboradas e avaliadas por especialistas de cada área e não pelos próprios jogadores. A inclusão de feedbacks para as respostas erradas, explicando por que o usuário errou determinada pergunta também auxiliaria na aprendizagem dos alunos. Outra sugestão de complementação do jogo para fins educacionais é alterar as suas configurações para possibilitar ao professor criar um grupo com alunos de uma mesma disciplina e usá-lo como uma atividade complementar em sala de aula ou online, onde ele atuaria como mediador. 


\section{Referências bibliográficas}

Botti, N. C. L., Mesquita, I. R., Pereira, C. C. M.\& Araújo, F. A. (2013).

Desenvolvimento e validação de software educativo de saúde mental. Revista Mineira de Enfermagem. Disponível em

http://www.reme.org.br/artigo/detalhes/920

Cheong, C., Cheong, F. \& Filippou, J. (2013). Quick Quiz: A Gamified Approach for Enhancing Learning. PACIS 2013 Proceedings, 206. Disponível em http://aisel.aisnet.org/pacis2013/206

Germano, A. S. M., Lopes, C. E. F., Aroca, S. C. \& Cunha, D. M. (2011). Integração do Quiz como ferramenta de aprendizagem numa disciplina de astronomia na modalidade a distância. In I Simpósio Nacional de Educação em Astronomia. (pp. 1-7), Rio de Janeiro, RJ. Disponível em http://snea2011.vitis.uspnet.usp.br/sites/default/files/SNEA2011 TCO3.pdf

Grübel, J. M. \& Bez, M. R. (2006). Jogos Educativos. Novas Tecnologias na Educação CINTED-UFRGS, 4 (2), 1-7. Disponível em http://www.seer.ufrgs.br/index.php/renote/article/view/14270/8183

Keskin, N. O \& Metcalf, D. (2011). The Current Perspectives, Theories and Practices of Mobile Learning. Turkish Online Journal of Educational Technology - TOJET, 10 (2), 202-208. Disponível em http://files.eric.ed.gov/fulltext/EJ932239.pdf

Medeiros, M. O. \& Schimiguel, J. (2012). Uma Abordagem Para Avaliação De Jogos Educativos: Ênfase No Ensino Fundamental. In V ENID - Encontro de Iniciação à Docência e XVI ENIC. São Paulo, SP. Disponível em http://revistapos.cruzeirodosul.edu.br/index.php/enic/article/viewFile/281/224

Mustardo, P. N. \& Mendonça, R. L. (2012). Imersão e Narrativa como elementos motivacionais em serious games. Revista Tecnologia Educacional, 33-51.

Mühlbeier, A. R. K., Mozzaquatro, P. M., Oliveira, L. C., Monteiro, T. B.\& Lopes, V. (2012). eNIGMA e M-Learning: jogo educativo trabalhando o raciocínio lógico através de dispositivos móveis. Revista Brasileira de Computação Aplicada, 4(2), 92-102. 
Ramos, C. A. L. \& Weiduschat, I. (1995). Jogar e Brincar: representando papéis, a criança constrói o próprio conhecimento e, consequentemente, sua própria personalidade. Disponível em http://www.posuniasselvi.com.br/artigos/rev0107.pdf

Silva, J. M. A., Canedo, R. V., Abrantes, T. A. S., Santos, R. T., Souza, R. A. \& Utagawa, C. Y. (2010). Quiz: um Questionário Eletrônico para Autoavaliação e Aprendizagem em Genética e Biologia Molecular. Revista Brasileira de Educação Médica, 34 (4), 607-614.

Tauroco, L. M. R., Roland, L. C., Fabre, M. C. J. M. \& Konrath, M.L. P. (2004). Jogos educacionais. Novas tecnologias na educação, CINTED-UFRGS, 2(1), 1-7.

Zh Tecnologia. Sucesso nas redes, Perguntados dá nova vida aos jogos de perguntas e respostas. Acessado em 3 de setembro de 2014, disponível em http://zh.clicrbs.com.br/rs/noticias/tecnologia/noticia/2014/06/sucesso-nasredes-perguntados-da-nova-vida-aos-jogos-de-perguntas-e-respostas4522082.html 